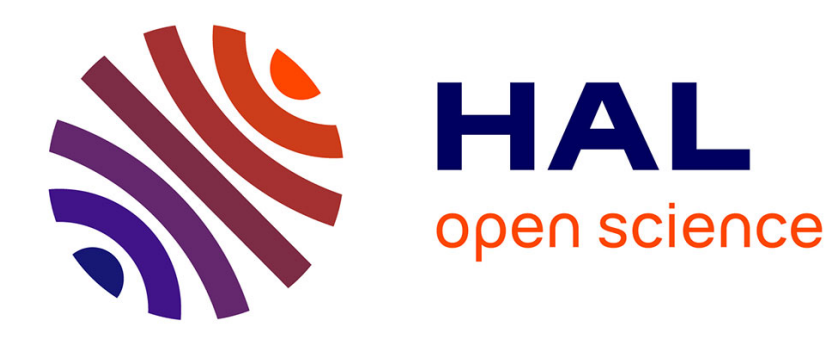

\title{
The implementation mechanisms of voluntary food safety systems
}

M'Hand Fares, Elodie Rouviere

\section{To cite this version:}

M'Hand Fares, Elodie Rouviere. The implementation mechanisms of voluntary food safety systems. Food Policy, 2010, 35 (5), pp.412-418. 10.1016/j.foodpol.2010.05.008 . hal-01323222

\section{HAL Id: hal-01323222}

\section{https://hal-agroparistech.archives-ouvertes.fr/hal-01323222}

Submitted on 30 May 2016

HAL is a multi-disciplinary open access archive for the deposit and dissemination of scientific research documents, whether they are published or not. The documents may come from teaching and research institutions in France or abroad, or from public or private research centers.
L'archive ouverte pluridisciplinaire HAL, est destinée au dépôt et à la diffusion de documents scientifiques de niveau recherche, publiés ou non, émanant des établissements d'enseignement et de recherche français ou étrangers, des laboratoires publics ou privés. 


\title{
The Implementation Mechanisms of Voluntary Food Safety Systems
}

\author{
M'hand FARES \\ INRA (UMR 1248 AGIR), Chemin de Borde-Rouge, BP 5262731326 Castanet-Tolosan cedex. France. \\ mfares@toulouse.inra.fr \\ \& \\ Elodie ROUVIERE \\ Agrosup Dijon (UMR CESAER), 26 bd Dr Petitjean, BP 8799921079 DIJON \\ elodie.rouviere@enesad.inra.fr
}

This version: March 2010

\begin{abstract}
The recent food scares have been the motivation for voluntary programmes on food safety being promoted by public authorities and voluntarily implemented by food operators. In this article, we take into account the nature of the contamination risk to investigate the complementarities between private and public mechanisms for those voluntary systems to be implemented by a firm. We show two main results. First, when the firm directly markets its products to consumers a strong mandatory threat is a sufficient condition to implement voluntary systems whatever the risk of contamination. In contrast, when the mandatory threat is weak voluntary systems should be more implemented in industries where the risk of food contamination is low (pesticide residue) than in industries where the risk of contamination is high (pathogenic contamination). Second, when the risk of food contamination is low and the firm is embedded in a supply chain where the retailer can impose its own safety system, a welldesigned penalty contract will induce a voluntary implementation whatever the mandatory threat.
\end{abstract}

Keywords: food safety; voluntary systems; co-regulation.

JEL Classification: D23, L22, Q18. 


\section{INTRODUCTION}

The recent food scares have been the motivation for voluntary programmes on food safety being promoted by public authorities and voluntarily implemented by food operators. We have empirical evidence that food operators are voluntarily adopting individual or collective quality management systems to guarantee food quality and/or safety and promote public health. For example, the British Egg Industry Council 10 years ago introduced the Lion Quality Scheme which sets high standards of food safety and animal welfare and currently accounts for $85 \%$ of egg production in the United Kingdom ${ }^{1}$. This cooperation between public authorities and firms has been tackled in the economics of food safety under the concept of co-regulation (García-Martinez et al., 2007, Codron et al. 2007, Rouvière-Caswell, 2010).

In this article we investigate the complementarities between private and public mechanisms that might induce voluntary implementation by food operators of quality management systems. We develop a formal analysis considering the behavior of one producing firm that might be under the influence of public authorities and/or a retailer who would impose their own quality management systems (respectively, mandatory or quasi-voluntary system). To better catch the specificities of the food safety issue, we rely on two points. First, we follow the definition of risk $^{2}$ provided by the Australia New Zealand Food Standards Council (ANZFA, 2002) distinguishing among two kinds of risks on the human health after a contamination episode: (i) a high risk when there is a pathogenic contamination, (ii) a low risk when there is a pesticide residue contamination. Second, we consider that food safety failures are "systemic in nature" (Hennessy et al., 2003) in the high risk situation. That is, all producers could suffer from a pathogenic contamination episode even if they are not responsible of the contamination. In 1998, the Federal Department of Agriculture of the Unites States of America published and promoted a voluntary guideline to "minimize microbial food safety hazards in the fresh fruit and vegetables industry" (Calvin, 2007). Calvin reports that most of spinach growers have voluntary used this framework to develop their own and

\footnotetext{
${ }^{1}$ http://www.britisheggindustrycouncil.com

${ }^{2}$ The Institute of Food Technologists for the Food and Drug Administration of the United States (2001) underlines that Australia, Canada, and the others governments (USA and the EU) share to some point this definition.
} 
voluntary food safety plans and that their compliance and practices have been certified by third party audits. However, following the fall 2006 spinach outbreak, the Economic Research Service of the United States Department of Agriculture reported that all US spinach growers suffered a drop in demand for their product ${ }^{3}$. Following a food scare, consumers lose confidence in the safety of products whatever preventive measures producers have implemented. After an outbreak all firms will suffer from a drop in demand because consumers indirectly lose their trust in the whole supply chain. Because of this systemic nature, we mainly show that in the high risk situation the voluntary measures will be implemented only when the threat to be imposed a mandatory system is strong. Otherwise, voluntary measures will be more easily implemented when the safety risk is low (pesticide residue contamination). We also show that when the safety risk is low and the retailer can impose its own safety system, a well-designed penalty contract will induce a voluntary systems implementation whatever the mandatory threat.

As far as we know, our approach differs from the theoretical literature on the implementation of voluntary food safety system. From our point of view, this literature has not adequately tackled all the specificities of the food safety issue when they have transposed the analytical framework developed in environmental economics. Indeed, it assumes that food operators always benefit from a voluntary adoption even after the occurrence of a contamination episode. Segerson (1999) shows that, because voluntary systems allows firms to save on costs and to benefit from reputation compared to a mandatory system, a firm will implement voluntary protective measures on food safety if there is a strong threat to be imposed a mandatory system. Building on her result, Venturini (2003) argues that a strong mandatory threat is a necessary but not a sufficient condition when relaxing the assumption on costs differential between voluntary and mandatory systems. Under this condition, he argues that governments must help food operators to signal safer foods allowing for instance firms' products to be stamped with an official label.

\footnotetext{
${ }^{3}$ Even though only one grower's spinach was contaminated.
} 
Our article departs from this literature by considering the more general setting where voluntary systems do not save on costs and where reputation benefit may vanish after the occurrence of a contamination episode. Then, we show that a strong mandatory threat is a sufficient condition to implement a voluntary system whatever the food safety risk considered. In contrast, when the mandatory threat is weak, we show that voluntary systems should be more implemented in industries with low food risk. Noelke and Caswell (2000) study the efficiency of food safety systems in the context of a supply chain. The authors have analysed the conditions under which a mandatory, quasi-voluntary or voluntary system implemented in a supply chain are more prevalent, that is leads to a higher level of food safety. They show that a voluntary system and a negligence liability rule always provide the highest level of food safety. However, their article does not deal with the implementation issue of those systems. Our article focuses on this issue and shows that private incentives provided by a retailer may implement voluntary systems whatever the mandatory threat.

Moreover, this article enlarges the current debate on the mix-up between public regulation and private standards on food safety. The "task sharing" that is developed in co-regulation programmes has been now at great place in the food safety industries in the US, the UK, Australia and in France (García-Martinez et al., 2007; Codron et al. 2007). The development of private standards or private regulation from supermarkets (Havinga, 2006) led scholars to develop research on different issues. Some of them bring out the impact of private standards on the food operators from developing countries (Minten et al., 2009) whereas others question the development of the certification market for food and the reliability of the certification process (Jahn et al., 2005). We follow up those researches establishing that in a co-regulation framework, to induce a voluntary implementation, retailers must recognize that voluntary systems performs as well as mandatory system or private standards in providing food safety.

The article proceeds as follows. In Section 2, we consider the decision of a producing firm who directly sells its products to consumers distinguishing between high food risk and low food risk. In Section 3, we deepen our analysis of the implementation of voluntary programmes within the supply chain considering that a task sharing between public authorities and retailers exists in monitoring food safety standard. In this context of co-regulation, we model the firm's decision when the firm is a supplier and might face to the requirements of a retailer. Section 4 
concludes.

\section{FOOD SAFETY RISK WITH DIRECT MARKETING}

In this section, we study a situation where the food operator directly markets its products to consumers (direct marketing). Following the previous literature (Segerson, 1999; Venturini, 2003) we will consider two mechanisms that can induce voluntary implementation of food safety measures by the food operator: (i) the regulator's ability to impose a mandatory improving food safety system ("stick" mechanism); (ii) economic and legal sanctions ("carrot" mechanism) that injured consumers might impose to the food operator.

\subsection{SET UP}

We consider a firm that directly sells to consumers a food product that can be unsafe. To reduce the risk of a contamination episode, the food operator plays a game against nature described in figure 1. At stage 1 , the food operator has to choose whether it implements a costly voluntary safety system or not. If the food operator decides not to implement voluntary safety measures, at stage 2 the regulator will intervene with a probability $r \in[0 ; 1]$. We assume that $r$ is an exogenous probability which reflects the probability that the regulator imposes a mandatory safety system to the firm. When $r=0$ there is no mandatory threat, albeit when $r=1$ the imposition of a mandatory system is certain. Whatever the firm's decision, a contamination episode can occur at stage 3 . If the firm does not adopt any voluntary safety measures and the regulator does not impose any mandatory safety measures, there will be a probability $p \in[0 ; 1]$ that a contamination episode occurs. When (voluntary or mandatory) safety measures are implemented, there is a probability $q \in[0 ; 1]$ of contamination. Since taking (voluntary or mandatory) safety measures can reduce contamination risks but does not allow to completely avoid it, we assume that $0 \leq q \leq p$ (Segerson, 1999). When a contamination episode occurs at stage 4 , consumers may sue the firm for damages whereas it is difficult for consumers to prove causality between consumption and illness (Buzby and Frenzen, 1999). Let $L$ denote the positive amount to be paid related to the judicial proceedings following a contamination episode. $L$ depends on the rule of liability which is operative regarding the payment of damages for injured consumers. Since the safety risks are different in nature, we assume that the amount to be 
paid related to the judicial proceedings are $L^{H}$ in the case of a high safety risk (pathogenic contamination) and $L^{L}$ in the case of low safety risk (pesticide residue contamination).

Concerning the payoff function of the firm, consider first the cost of implementing safety measures. Let $C_{V}$ and $C_{M}$ be the costs that the firm bears when it reaches a given (and the same level) of food safety through respectively a voluntary and a mandatory safety system. Following the voluntary approach literature in environmental economics, Segerson (1999) assumes that the compliance costs associated to the implementation of a mandatory safety system (training employees, record keeping equipment, etc.) are higher than those associated to the implementation of a voluntary one. In contrast, Venturini (2003) suggests that such a cost differential is not supported by empirical evidence on the implementation of safety system such as HACCP ${ }^{4}$. Therefore, in what follows we suppose that there is no cost differential, i.e. $\Delta C \equiv C_{M}-C_{V}=0$.

Consider now the firm's benefit of implementing safety measures. We split the gross benefit of implementing voluntary measures in three components. That is $B_{V}=B_{0}+B_{D}+B_{R}$, where $B_{0}$ reflects the net and direct revenue from product sales, $B_{D}$ the direct market benefit due to an increased demand for its product as a result of a higher safety ${ }^{5}$, and $B_{R}$ the benefit due to the firm's stock of reputation because of its voluntary implementation. Similarly, when the regulator imposes a mandatory safety system to the firm, the firm will receive $B_{M}=B_{D}+B_{0}$. When no safety measures (voluntary or mandatory) are implemented, it only receives $B_{0}$ which is the minimum benefit the firm can get. Moreover, since the direct market benefit $B_{D}$ is the same whether the firm implements a voluntary or a mandatory safety system, the "incentive" component for a firm to adopt voluntary safety measures is $B_{R}$, that is the benefit due to its stock of reputation because of its voluntary implementation.

At this point, we differ from the literature on voluntary programmes because we attempt to tackle some food

\footnotetext{
${ }^{4}$ See Colatore and Caswell, 1999; Zaibet and Bredhal, 1997; Unnevehr, 1999. For example, Colatore and Caswell (1999) show that for eight breaded fish companies the costs adoption of a mandatory HACCP raises the annual total costs of only $0.25 \%$.

${ }^{5}$ There is evidence that consumers and firms are willing to pays more for safer foods (Shin et al. 1992).
} 
safety specificities. Indeed, we assume that after a contamination episode the benefit component of reputation $B_{R}$ can be altered, even if $B_{R}$ still remains nonnegative. Indeed, the firm can loose its "good reputation" because of food contamination ( $B_{R}$ can decrease to 0 ). But, this depends on demand response following a contamination episode. We distinguish two cases ("high safety risk" and "low safety risk") assuming that consumers' response will differ on the consequences of a contamination on human health.

\subsection{CASE 1: "HIgh SAFETY RISK".}

We refer here to situations where contamination episode can have immediate and strong consequences (lethal) for consumers. Therefore, we consider a situation with a high safety risk. We particularly point out here the pathogenic risk where products contamination can be lethal for consumers (e.g. in the fresh meat or fish industries even in the fresh produce). In 2006, in the US, 141 hospitalizations (31 people having kidney failure, and 3 people died) have been attributed to the E. coli outbreak on fresh spinach (Surak, 2007). One consequence of such outbreak is that the response from the market was very strong. Demand falls to zero and the outbreak erodes all producers' reputation and might lead them to bankrupt. Moreover, injured consumers might sue food operators for damages. The Peanut Corporation of America (PCA) is also a good example of such economic and judicial stakes. The PCA was a family-owned and operated business since 1976 that bankrupted in 2009 after a very wide salmonella contamination of its product. In the same time, consumers' complaints have been multiplied to sue the company for damages.

In this "high safety risk" situation, when the firm has undertaken a voluntary safety system and no contamination episode follows, it gets the net full return $\left(B_{V}-C_{V}\right)$ from voluntarily increasing products safety. In contrast, when a contamination episode occurs with a probability $q$ the firm will only get $B_{0}-C_{V}-L^{H}$. Indeed, in such a case the strong consumers' response has two consequences. First, the benefit decreases from $B_{V}$ to $B_{0}$ since the reputation and the increased demand components associated to improving food safety measures disappear (i.e. $\left.B_{D}=B_{R}=0\right)$. Second, the firm must pay additional fees $L^{H}$ due to legal proceedings. Therefore, the expected payoff that a firm gets when it implements voluntary safety measures is $q\left[B_{0}-C_{V}-L^{H}\right]+(1-q)\left[B_{V}-C_{V}\right]$. 
When the firm takes no voluntary safety measures and the regulator will impose a mandatory safety system, the reputation component in the benefit will also vanish since the measures are mandatory. Therefore, the net return from increasing the safety is $B_{M}-C_{M}$. When no safety measures have been implemented (voluntary or mandatory), the gross benefit reduces to the minimum gross benefit $B_{0}$. In both situations, the occurrence of a contamination episode implies only a reduction of the expected losses relative to the payments of damages $L^{H}$. Therefore, the expected payoff that a firm gets when no voluntary measures are undertaken is $r\left(q\left[B_{0}-C_{M}-L^{H}\right]+(1-q)\left[B_{M}-C_{M}\right]+(1-r)\left[B_{0}-p L^{H}\right.\right.$. Then implementing a voluntary safety system is an equilibrium if:

$$
q\left[B_{0}-C_{V}-L^{H}\right\rfloor+(1-q)\left[B_{V}-C_{V}\right] \geq r\left(q\left[B_{0}-C_{M}-L^{H}\right\rfloor+(1-q)\left[B_{M}-C_{M}\right]+(1-r)\left\lfloor B_{0}-p L^{H}\right\rfloor\right.
$$

or equivalently

$$
q B_{0}-C_{V}-q L^{H}+(1-q) B_{V} \geq r\left\lfloor q B_{0}-C_{M}-q L^{H}+(1-q) B_{M}\right\rfloor+(1-r)\left\lfloor B_{0}-p L^{H}\right\rfloor
$$

When the regulator imposes mandatory measures if the firm does not voluntarily adopt safety measures $(r=1)$, then condition (1) becomes

$$
(1-q)\left(B_{V}-B_{M}\right) \geq\left(C_{M}-C_{V}\right)
$$

or

$$
(1-q) B_{R} \geq \Delta_{C}
$$

And condition (2) implies that the reputation component of the benefit $\left(B_{R}\right)$ must outweigh the cost differential $\Delta_{C}$. Since $\Delta_{C}=0$ by assumption, condition (2) is then

$$
(1-q) B_{R} \geq 0
$$

which always holds because $B_{R}$ is positive. Even if the firm has no reputation, that is $B_{R}=0$, condition (2) is trivially satisfied. Therefore, the threat to be imposed a mandatory system is a sufficient condition to induce the 
firm to implement voluntary safety measures.

In this section, we consider that food safety outbreaks might alter the reputation of the firm. The existence of this reputation effect can emphasize the voluntary implementation by food operators. That is, when the threat of being imposed a mandatory programme is low $(r=0)$, condition (1) becomes

$$
q B_{0}-C_{V}-q L^{H}+(1-q) B_{V} \geq B_{0}-p L^{H}
$$

or equivalently,

$$
(1-q)\left(B_{D}+B_{R}\right)+(p-q) L^{H} \geq C_{V}
$$

This implies that when the mandatory threat is weak the adoption of a voluntary safety system depends on two complementary mechanisms: a "carrot" and a "stick". The "carrot" is the two components of the benefit $\left(B_{D}+B_{R}\right)$ that increases with the adoption of voluntary measures. However, in the food safety case ( $\left.B_{D}+B_{R}\right)$ can be very low because of food safety signalling problems to consumers. For example in France, signalling food safety is indirectly prohibited by law (Codron et al., 2007). Second, the "stick" is the expected losses due to judicial proceedings $\left((p-q) L^{H}\right)$ following a contamination episode. Full traceability and the design of an efficient legal rule are then a crucial issue. For example, a rule of negligence can be an efficient solution to implement voluntary safety measures (Noelke and Caswell, 2000). Indeed, under the rule of negligence, when a contamination episode occurs the firm will be held liable if the level of the safety system it has implemented is lower than what the court could expect. This negligence rule will be effective if full traceability operates in the supply chain. This implies however that without such a constraining legal rule, the voluntary safety measures can be implemented only when the mandatory threat is strong.

\subsection{CASE 2: "LOW SAFETY RISK"}

Here, we consider a situation where the appraisal of safety risks and contamination occurrence is quite difficult and costly to monitor. In this case, we argue that the safety risk is "low" because of very low probabilities of strong and instant consequences for human health after food intake. This is the case with pesticides issues in the fresh fruit and vegetable industry. Most of the time consumers are not fully aware about health problems linked to 
consumption of contaminated fruit and vegetables, which primarily have not instant but can have cumulative effects $^{6}$. In this case, economic and legal sanctions could be very low because of the difficulties to link the contamination to a particular product and then to a particular producer (Buzby and Frenzen, 1999).

In the case of a contamination, the firm benefit is supposed to be softly affected since consumers are unaware about the consequences of a contamination episode. In others words, the firm will get all the net (full) return $\left(B_{V}-C_{V}\right)$ from implementing a voluntary food safety system even if a contamination episode occurs. Given this slight modification in the firm payoff, choosing voluntary measures is an equilibrium if

$$
B_{V}-C_{V}-q L^{L} \geq r\left(B_{M}-C_{M}-q L^{L}\right)+(1-r)\left(B_{0}-p L^{L}\right)
$$

As previously, we consider two extreme cases that rely on the ability of public authorities to impose a mandatory standard. When the mandatory threat to be imposed safety measures is certain $(r=1)$, the firm will adopt voluntary measures if and only if

$$
B_{V}-C_{V}-q L^{L} \geq B_{M}-C_{M}-q L^{L}
$$

The inequality always holds if $B_{R} \geq 0$ since $B_{R}$ is nonnegative. This implies that no additional constraint is needed to implement a voluntary safety system when the mandatory threat is credible. Indeed, even if $B_{R}$ is equal to zero, there will be no gain to have a good reputation and condition (5) is trivially satisfied.

When the threat to be imposed a mandatory system is weak $(r=0)$, condition (4) becomes

$$
B_{V}-C_{V}-q L^{L} \geq B_{0}-p L^{L}
$$

or,

$$
\left(B_{D}+B_{R}\right)+(p-q) L^{L} \geq C_{V}
$$

\footnotetext{
${ }^{6}$ The European Food Safety Authority (EFSA) takes forward the results of on-going work to develop methodologies to assess the cumulative effects resulting from consumer exposure to pesticides.
} 
Like in the situation where the risk is high, the voluntary implementation of a safety system depends on the same two mechanisms (stick and carrot), which must outweigh the costs induced by a voluntary implementation $C_{V}$. Therefore, a good reputation and an efficient rule of liability can a priori respectively play the role "carrot and stick". However, such a rule can be hard to design since civil litigations cannot be efficient when consequences of a contamination episode are not instant and when it can take decades for people to get sick. Consumers cannot sue a firm which failed to provide safe goods because it is both difficult and costly, and most of the time very hard, to prove the real nature of a contamination. One solution is to link the rule of liability not to the "outcome" (is there a contamination?) but to the "process" (does the firm comply with the monitoring plan designed by the regulator?).

Table 1. Synthesis of results

\begin{tabular}{|ccc|}
\hline & High food risk & Low food risk \\
\hline Strong Mandatory threat & $(1-q) B_{R} \geq 0$ & $B_{R} \geq 0$ \\
\hline Weak Mandatory threat & $(1-q)\left(B_{D}+B_{R}\right)+(p-q) L^{H} \geq C_{V}$ & $\left(B_{D}+B_{R}\right)+(p-q) L^{L} \geq C_{V}$ \\
\hline
\end{tabular}

The table 1 above shows two main results. First, whatever the very nature of the risk, a strong threat to impose a mandatory system will always lead to a voluntary implementation from the firm. In contrast to Segerson (1999), we show that this result holds even when the voluntary system has no cost advantage (i.e. $C_{V}=C_{M}$ ). Second, when the mandatory threat is weak, the voluntary systems implementation is much easier in a low risk situation (pesticide contamination) than in a high risk situation (pathogenic contamination) since

$$
\left(B_{D}+B_{R}\right)+(p-q) L^{L} \geq(1-q)\left(B_{D}+B_{R}\right)+(p-q) L^{H}
$$

Only when an efficient legal rule, such as the rule of due diligence in the United Kingdom, is operative condition (7) could be reversed. However, this holds if the judicial proceedings in a high food risk situation ( $\left.L^{H}\right)$ is such that

$$
L^{H} \geq L^{L}+\frac{q}{(p-q)}\left(B_{D}+B_{R}\right)
$$


And the higher the probability of a contamination episode $(q)$, the higher must be the optimal judicial proceedings. As a consequence and upon empirical evidence, voluntary system are less implemented in industries when the food safety risk is high. That is why in the United States, since 1996 the Pathogen Reduction Hazard Analysis Critical Control Point (HACCP) has been introduced for the meat and poultry industries (Loader and Hobbs, 1999). And HACCP became also mandatory in the seafood industry in 1999 and in 2001 in juices industries. In contrast in the United States, when the food risk is low (pesticide contamination) such as in the fresh fruit and vegetable industry, the implementation of HACCP remains voluntary for growers.

\section{LOW FOOD RISK IN THE SUPPLY CHAIN}

In the previous section, we have shown that voluntary systems can be more easily implemented in a low food risk situation than in a high food risk situation. However, the "stick and carrot" mechanism that sustains this implementation may not be efficient. Indeed, the market "carrot" (i.e. the increased benefit $\left(B_{D}+B_{R}\right)$ when choosing voluntary systems) as well as the judicial "stick" ( $\left.(p-q) L^{L}\right)$ can be very low., Indeed, ince consumers cannot sue a firm which failed to provide safe goods because it is both difficult and costly to prove the real nature effect of a pesticide contamination.

In this section, we deepen our analysis on the implementation of voluntary programmes in a situation of low food risk considering a more general case. We analyse the behaviour of a producing firm that is operating in the supply chain and might be under the influence of a retailer who can impose its own quality management systems. Quality management system have emerged in the supply chain in order to mainly control the specific food safety hazards and ensure compliance with food safety regulation (Henson and Heasman, 1998; Caswell et al., 1998; Loader and Hobbs, 1999). Following Noelke and Caswell (2000), we define the quality management system imposed by retailers as quasi-voluntary. Indeed, without any explicit prompting by the regulator the firm can be forced by the retailer to implement safety measures. This system is not really voluntary since the firm will have to implement the system if it wants to keep its contract. In contrast, when the firm implements a voluntarily system, it makes it without any explicit prompting, neither by the retailer nor by the regulator.

This leads us to highlight the key feature of co-regulation on food safety: that is the "task sharing" between the 
regulator and the retailer. Indeed, the regulator is supposed to design and set the Minimum Quality Standard (MQS). In most cases, MQS are performance standard (Maximal Limits or pesticides Residues in fruit and vegetable). With performance standard (e.g. pathogen counts for products at some stage of the supply chain) public authorities require food operators to achieve prescribed product quality standards but means to reach the standard are not specified (Henson and Caswell, 1999). The retailer will enforce the MQS by monitoring its supplier's compliance and providing incentives of doing so. The retailer can be induced to undertake this costly monitoring either because there is a liability rule that makes him liable for a contamination episode (Henson and Hooker, 2001; Northen, 2001 in the UK), or because the retailer is a guarantor of quality. Biglaiser-Friedman (1994) show that because a large scale retailer (like a supermarket) is an intermediary that sells a large volume and very different kinds of products. The middleman engages in this policing activity in order to maintain its own reputation as a seller of high quality goods, since high-volume sellers will have more at stake if their reputations are destroyed.

\subsection{Set up}

To integrate the role of the retailer, the previous decision game of the firm is slightly modified (see figure 2 ). At first, the retailer offers a take-it-or-leave-it contract. If the firm accepts such a contract, the game will continue and the firm will supply the retailer. Then, the firm chooses to implement or not a voluntary safety system. If the firm does not implement a voluntary safety system, the regulator will impose a mandatory system with a probability $r(0,1)$. If the regulator does not impose a mandatory safety system the retailer will impose its quasivoluntary safety system with a probability $s \in(0,1)$. According to the "task-sharing" principle that exist in coregulation programmes the retailer is supposed to only test the compliance of its supplier with MQS set and designed by the government. In others words, the retailer does not want to reach a higher level of food safety by imposing its own safety systemstandard. The firm does not comply with the retailer safety testing with a probability $q \in(0,1)$, whatever the system the firm has implemented.

The payoff functions of the firm are also slightly modified. Concerning the cost notations, let $C_{C}$ be the cost associated to the implementation of the retailer's system (quasi-voluntary safety measures). For example, $C_{C}$ can be the certification costs that the firm must bear when the retailer requires a third-party private certification. 
Similarly, let $B_{C}$ represent the benefits that the firm receives when it implements a quasi-voluntary safety system. We assume that there is no benefit advantage to implement a quasi-voluntary safety system rather than a voluntary one, that is $B_{V}=B_{C}=B_{R}+B_{D}+B_{0}$. Finally, the introduction of a retailer implies that it can design a menu of contracts $\left(P_{1}, P_{2}, P_{3}, P_{4}\right)$, where $P_{i}$ denote the private penalties that the firm must pay to the retailer when it does not comply with the public standard. More precisely, $P_{1}$ is associated to a failure with a voluntary safety system, $P_{2}$ with a mandatory system, $P_{3}$ with a quasi-voluntary system, and $P_{4}$ is applied when the firm undertakes no safety measures. We assume that $P_{4} \geq P_{3}$, that is the penalty is higher when the firm does not implement any safety measures than when the retailer has imposed its own system (quasi-voluntary system).

\subsection{PRIVATE INCENTIVES AND VOLUNTARY ADOPTION}

As in the section 2, we consider two situations according to the threat of being imposed a mandatory system by public authorities. If the mandatory threat is certain $(r=1)$, then we get

$$
B_{V}-C_{V}-q P_{1}-q L^{L} \geq B_{M}-C_{M}-q L^{L}-q P_{2}
$$

or equivalently,

$$
B_{R}+q\left(P_{2}-P_{1}\right) \geq 0
$$

Since $B_{R}=0$ because of the safety attribute there are no reputation effects and $q$ is nonnegative, then condition (8) becomes

$$
P_{1} \leq P_{2}
$$

In the supply chain model, a strong mandatory threat is a necessary but not a sufficient condition to induce a voluntary adoption. In this case, we need an additional constraint regarding the penalty a retailer might impose following a safety failure. The penalty associated to the voluntary system must be lower than the penalty associated to a mandatory system.

We now consider the general case where the probability to be imposed a mandatory standard is low $(r=0)$ and 
where the retailer can impose its own safety monitoring system with a probability $0 \leq s \leq 1$. In such a case, a voluntary strategy is an equilibrium if

$$
B_{V}-C_{V}-q P_{1}-q L^{L} \geq s\left(B_{C}-C_{C}-q P_{3}-q L^{L}\right)+(1-s)\left(B_{0}-q P_{4}-q L^{L}\right)
$$

that is,

$$
(1-s)\left(B_{D}+B_{R}\right)+s q\left(P_{3}-P_{4}\right)+s C_{C} \geq C_{V}+q\left(P_{1}-P_{4}\right)
$$

This implies that when $s=0$, i.e. the retailer does not impose its own (quasi-) voluntary safety system, then

$$
P_{1} \leq P_{4}+\frac{\left(B_{D}+B_{R}\right)-C_{V}}{q}
$$

And when $s=1$, i.e. the retailer does impose its own (quasi-) voluntary safety system, then

$$
P_{1} \leq P_{3}+\frac{C_{C}-C_{V}}{q}
$$

This implies that in a supply chain, private incentives provided by the retailer can be a very powerful mechanism. Indeed, a well-designed menu of penalties will induce voluntary safety measures adoption. Indeed, if the retailer sets $P_{1}$ such that $P_{1}=\min \left\{P_{2}, P_{3}+\frac{C_{C}-C_{V}}{q}, P_{4}+\frac{\left(B_{D}+B_{R}\right)-C_{V}}{q}\right\}$, then the firm will implement voluntary measures. And this holds whatever the mandatory threat, or the probability that the retailer imposes its own safety system. In others words, private incentives can be used as a unique mechanism to induce the voluntary adoption of safety measures upstream firms.

\section{CONCLUDING REMARKS}

The recent evolution of European food safety regulations is characterised by the increased involvement and responsibility of private actors in food safety controls. The 2001 European Regulation (EC) No 178/2002 that came into in force in 2005 had this objective. This article focuses on complementarities between private and public mechanisms for those systems to be voluntary implemented by food operators taking the specificities of the food safety. We argue that these mechanisms can be ranked according to the threat to be imposed a mandatory system 
by public authorities and the type of food safety risk. We suggest that voluntary systems should be much more implemented in industries where the food safety risk is low.

We then analyse the decision of a firm that is operating within a supply chain and might under the influence of retailer. The retailer monitors its supplier's compliance with minimum quality standard set and designed by public authorities. In this context of co-regulation, the retailer can design an incentive scheme such that voluntary systems will be implemented whatever the mandatory threat, or the probability that the retailer imposes its own safety system. The limit of this approach is that the retailer can also monitor the firm compliance for "bad" reasons. That is, it can also use strategically the delegated monitoring decision rights to increase its bargaining power in the negotiation or the renegotiation of its procurement contracts (Codron et al, 2007).

Further research should take into account the purpose and the extent of such task sharing and delegated monitoring decision rights in co-regulation programmes to food safety. Moreover, it will be interesting to introduce moral hazard in the relationship between the firm and the retailer and have a look on their strategic interactions. That is, we should consider the possibility that the detection probabilities are endogenous and determined by the upstream firm effort in monitoring its own safety system. Then, we need to consider the situation where the retailer decides to impose its private standard higher than the public one, and how does the potential competition between standards affect the extent of co-regulation. 


\section{REFERENCES}

Australia New Zealand Food Authority -ANZFA (2002), Annual Report 2001-2002, 204p;

Biglaiser, G., and Friedman J. (1994), “Middlemen as Guarantors of Quality," International Journal of Industrial Organization, 12, 509-531.

Calvin L., B. Avendaño and R. Schwentesius. (2004), The Economics of Food Safety: The Case of Green Onions and Hepatitis A Outbreaks. Washington DC: U.S. Department Agriculture,Outlook Report No. (VGS30501).

Buzby, J. and Frenzen, P. (1999) Food Safety and Product Liability. Food Policy, 24(6), pp. 637-51.

Caswell, J., Bredahl M., and Hooker N. (1998), "How Quality Management Metasystems are Affecting the Food Industry." Review of Agricultural Economics. 20(2), pp. 547-557.

Codron J.M., Fares M. and Rouvière E., (2007), From Public to Private Safety Regulation? The Case of Negotiated Agreements in the French Fresh Produce Import Industry, International Journal of Agricultural Resources, Governance and Ecology, 6(5), pp. 415-42.

Colatore, C. and Caswell, J. (1999), The Costs of HACCP Implementation in the Seafood Industry: A Case Study of Breaded Fish. In Unnevehr, L. (ed) The Economics of HACCP: New Studies of Costs and Benefits, Eagan Press

Havinga, T., (2006), Private Regulation of Food Safety by Supermarkets, Law \& Policy, Vol. 28(4) pp. 515-533.

Garcia-Martinez, M., Fearne, A., Caswell, J., Henson, S., (2007), Co-regulation as a possible model for food safety governance: Opportunities for public-private partnerships. Food Policy 32(3), 299-314.

Hennessy, D.A., Roosen, J., Jensen, H. (2003), Systemic failure in the provision of safe food, Food Policy 28(1), pp 77-96.

Henson, S. and Caswell, J., (1999), Food Safety Regulation: An Overview Of Contemporary Issues. Food Policy. 24(6), pp. 589-603.

Henson, S. and Heasman, M. (1998), Food Safety Regulation and the Firm: Understanding the Compliance Process, Food Policy, 23(1), pp. 9-23.

Henson, S. and Hooker, N. (2001), Private Sector Management of Food Safety: Public Regulation and the Role of Private Controls, The International Food and Agribusiness Management Review, 4(1), pp. 7-17.

Institute of Food Technologists (IFT) (2001), Current and Proposed Definitions of Potentially Hazardous Foods. In Evaluation and Definition of Pazardous Foods. http://www.fda.gov/Food/ScienceResearch/ResearchAreas/SafePracticesforFoodProcesses/ucm094141.htm

Jahn, G., Schramm, M. and Spiller, A. (2005), The Reliability of Certification: Quality Labels as a Consumer Policy Tool. Journal of Consumer Policy, 28(1): 53-73

Loader, R. and Hobbs, J. (1999), Strategic Responses to Food Safety Legislation, Food Policy, 24(6), pp. 685-706.

Minten, B., Randrianarison L., and Swinnen, J. (2009), Global retail chains and poor farmers: Evidence from Madagascar World Development 37(11), pp 1728-1741.

Noelke, C. M. and Caswell J. (2000), "A Model of the Implementation of Quality Management Systems for Credence Attributes.," Paper selected at the AAEA Annual Meeting. Tampa, Florida, 28p.

Northen, J. (2001), Using Farm Assurance Schemes to Signal Food Safety to Multiple Food Retailers in the U.K., The International Food and Agribusiness Management Review, 4(1), pp. 37-50.

Rouvière, E. and Caswell, J. (2010), From punishment to prevention: the introduction of co-regulation programmes in the enforcement of food safety. Unpublished.

Segerson, K. (1999), Mandatory Versus Voluntary Approaches to Food Safety, Agribusiness, 15(1), pp. 53-70.

Shin, SY., Keilbenstein, J., Dermot, J. and Shogren, J. (1992), Consumer Willingness to Pay for Safer Food Products. 
Journal of Food Safety 13, pp. 51-59.

Surak, J.G. (2007), A Recipe for Safe Food: ISO 22000 and HACCP Quality Progress 40(10), pp. 21-

Unnevehr, L. (1999), The Economic Implications of Using HACCP as a Food Safety Regulatory Standard, Food Policy, 24(6), pp. 625-35.

Venturini, L. (2003), Public Regulation and Voluntary Approaches to Food Safety Credence Good, G. Schiefer, Rickert U., Quality Assurance, Risk Management and Environmental Control in Agriculture and Food Supply Networks. Bonn: Universität Bonn-ILB, Germany, pp.265-69.

Zaibet, L. and Bredahl, M. (1997), Gains From ISO certification in the UK Meat Sector, Agribusiness, 13(4), pp. 375384. 
Figure 1

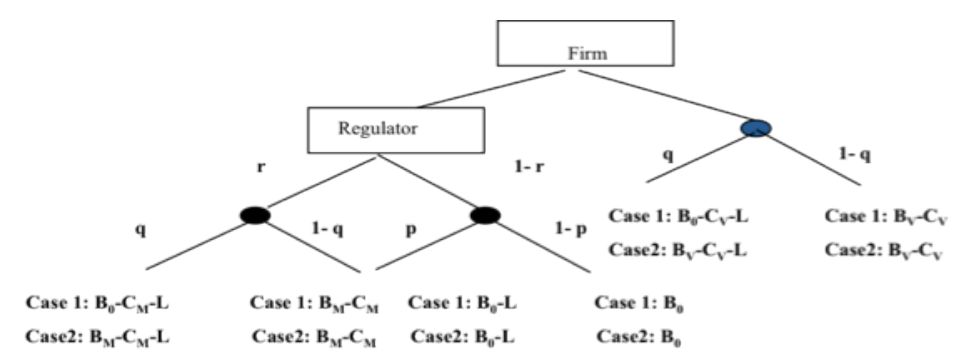

Figure 2

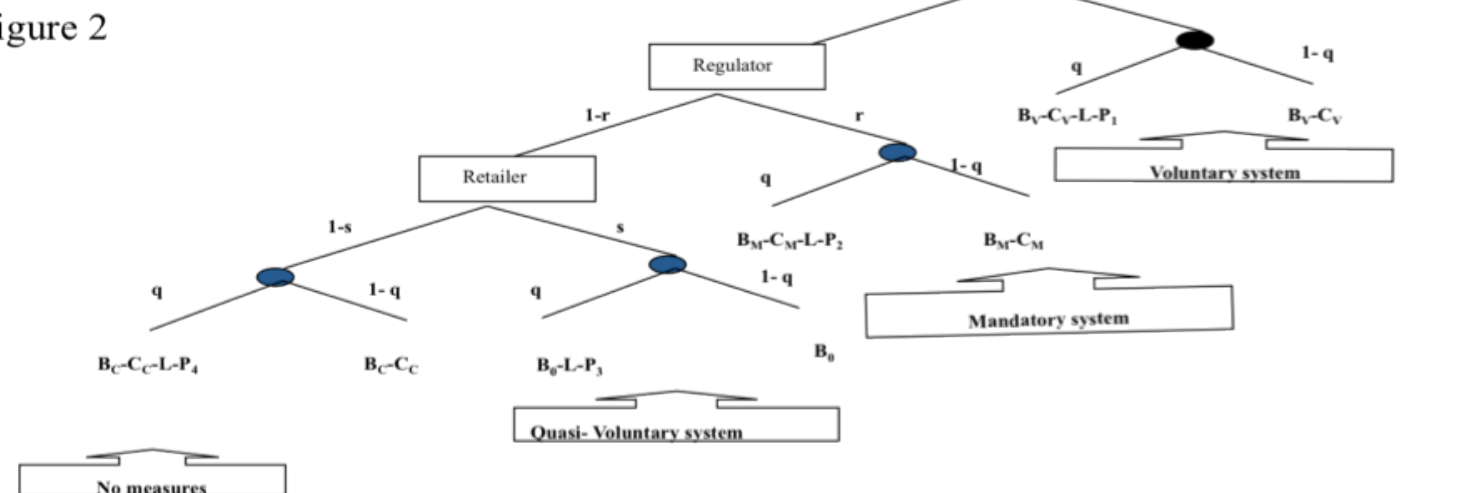

